\title{
La teoría de la comunicación, las relaciones públicas y la investigación: una relación simbiótica
}

\author{
Nora Elena Botero Escobar ${ }^{\star \star}$
}

Recibido: 20 de febrero de 2012 Aprobado: 27 de marzo de 2012

\begin{abstract}
Resumen
Este artículo se constituye en uno de los resultados de la investigación: "Caracterización del campo de investigación sobre lo público, lo político y lo privado en el marco de las relaciones públicas", proyecto adelantado desde la Facultad de Comunicación de la Universidad de Medellín y que fijó como objetivo, el delimitar el campo de lo público, lo político y lo privado en el espacio de las relaciones públicas, y generar así unas líneas de investigación que puedan ser alimentadas por la comunidad académica de la facultad.
\end{abstract}

Con este aparte de la investigación se busca dejar clara la relación existente entre el desarrollo teórico y el práctico de las relaciones públicas con base en las investigaciones que sendos teóricos desarrollaron para explicar los efectos de los procesos persuasivos de la comunicación en las personas. Es precisamente en la "persuasión" donde se encuentra la mayor unión entre los dos conceptos, y es la investigación el principal hilo para generar una simbiosis marcada por la dependencia de la disciplina (relaciones públicas) a la teoría (ciencias de la comunicación).

Palabras clave: teoría de la comunicación, relaciones públicas, persuasión, funcionalismo, estructuralismo, teoría crítica.

* El presente artículo es resultado de la investigación: "Caracterización del Campo de Investigación sobre lo público, lo político y lo privado en el marco de las Relaciones Públicas", proyecto adelantado desde la Facultad de Comunicación de la Universidad de Medellín

* Comunicadora social-periodista egresada de la Universidad de Antioquia, especialista en Mediación Social de la Universitat Jaume I de Castellón de la Plana (España), magíster en Comunicación Educativa de la Universidad Tecnológica de Pereira en Convenio con la Universidad de Medellín. Docente Universitaria en el Área de Comunicación y Relaciones Públicas. Profesora de tiempo completo de la Universidad de Medellín. Correo electrónico: nebotero@udem.edu.co 


\title{
Communication Theory, Public Relations, and Research: A Symbiotic Relationship
}

\begin{abstract}
This article is the result of the research "Characterization of the Research Field on What is Public, What is Politic, and What is Private, on the Frame of Public Relations," a project developed from Universidad de Medellin Communication Faculty and which objective was to define the field of what is public, what is politic, and what is private in the space of public relations, thus generating a research line which may be fed by the School academic community.

With this research, it is searched to delimit existing relation between theoretical and practical development of public relations based on researches which theoreticians developed in order to explain the effects of persuasive processes of communication among people. It is precisely in "persuasion" in which the largest union between the two concepts has been found and the research is the main link to generate a marked symbiosis by the dependence of the discipline (public relations) from theory (communication sciences).
\end{abstract}

Key words: Communication theory, public relations, persuasion, functionalism, structuralism, critical theory. 


\section{INTRODUCCIÓN}

Cuando buscamos establecer una relación entre la teoría de la comunicación y las relaciones públicas, es obligación teórica aclarar que la primera abarca a la segunda; es decir, las relaciones públicas como técnica y disciplina encuentran en la comunicación su principal instrumento para desarrollarse, para convertirse en realidad. El uso de los medios de comunicación y de las herramientas de persuasión fundamentadas en el lenguaje oral y escrito ha hecho de las relaciones públicas una disciplina de amplio reconocimiento en Estados Unidos y Europa, configurando una profesión de alto lucro y de consolidada posición social.

Pero para comenzar a abordar el tema que nos ocupa, la relación conceptual entre ciencia (la comunicación) y disciplina (las relaciones públicas), miremos cómo se sitúa nuestra disciplina en los paradigmas de la teoría de la comunicación.

Como es de amplio conocimiento en los espacios académicos, la teoría de la comunicación encuentra asidero en tres modelos, a saber: el funcionalismo, el estructuralismo y la teoría crítica, paradigmas que han dado como resultado una multiplicidad de escuelas y movimientos que, a su vez, han tenido como objeto de estudio la comunicación humana. He aquí otro hilo que relaciona ambos conceptos: la amplia investigación que se ha gestado alrededor de dicho objeto, la misma que dio pie a la construcción teórica tanto de la ciencia de la comunicación como a la disciplina de las relaciones públicas.

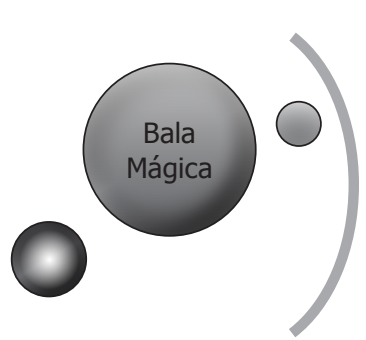

EFECTOS OMNIPOTENTES

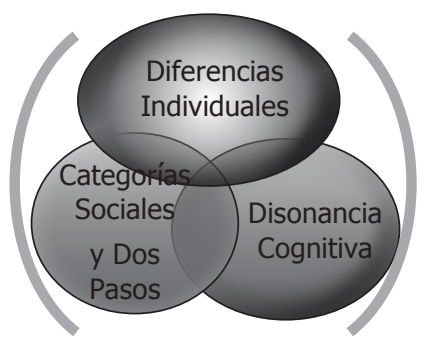

EFECTOS LIMITADOS

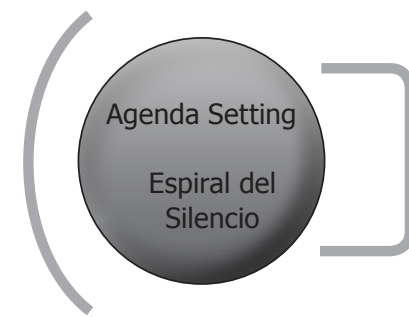

EFECTOS IMPORTANTES COGNITIVOS

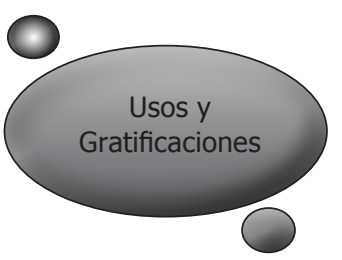

AUDIENCIAS ACTIVAS
Fuente: elaboración propia 
Es en estas teorías desarrolladas desde una óptica funcionalista, donde comenzamos a encontrar la relación de subordinación de la disciplina de las relaciones públicas a la teoría de la comunicación como ciencia. Lo que hicieron los investigadores que desarrollaron estas teorías fue medir los efectos de las acciones de relaciones públicas que utilizaron la persuasión como instrumento para cambiar mentalidades, y así mejorar la imagen de las organizaciones políticas, públicas o privadas que hacían uso de estas técnicas de manera empírica, como se puede constatar en los modelos de relaciones públicas que Grunig (2000) define en su libro Dirección de relaciones públicas, especialmente en el modelo que él mismo llamó, Publicity o Agente de Prensa. Grunig expresa que este modelo de acción de las relaciones públicas se fundamenta en la desinformación para manipular el mensaje y adaptarlo a la conveniencia del emisor.

Hagamos un corto recorrido por las teorías antes mencionadas, iniciando por aquella donde se consideraba a los medios absolutamente omnipotentes. Aquí encontramos la teoría de la "bala mágica", también llamada posteriormente la teoría de la "reacción en cadena". Esta se fundamenta en el concepto de la sociedad de masas, entendida como un conjunto de personas uniformes en pensamiento y acción, fuertemente influenciables por los mensajes emitidos a través de los medios de comunicación. Por lo tanto, la audiencia que estaba conformado por esa masa era vista como indefensa ante los medios, toda vez que como individuos se encontraban aislados psicológicamente, sus interacciones sociales predominantemente eran impersonales y, por consiguiente, no se sentían afectados por los vínculos sociales. Adicionalmente, desde la psicología, debido a la demanda de los militares, la industria, y los partidos políticos, se comenzaron a aplicar de manera premeditada técnicas de comunicación persuasiva, que fueron claves para el Ejército norteamericano en el logro del éxito en ambas Guerras Mundiales y para posicionarse como potencia bélica en el mundo. Por su parte, la industria vio en el uso de estas comunicaciones persuasivas una excelente oportunidad para aumentar el consumo de sus productos, y fue así como empezó a utilizar la publicidad. Igualmente, los partidos políticos hicieron uso de este tipo de mensajes persuasivos, en tanto la opinión pública adquirió mayor influencia para alcanzar su acceso al poder.

El enfoque de este tipo de mensajes estaba determinado por la psicología conductista, partiendo del precepto que esgrime que la conducta se puede intervenir de forma predecible a partir de un determinado estímulo. Aquí se sustenta la hipótesis de la omnipotencia de los medios y de su alta influencia en una masa que se establecía desde la sociología como homogénea, asilada en su propia igualdad y pasividad. A través del empirismo, varios investigadores observaban cómo las masas se rendían ante el poder ilimitado de los mensajes que se emitían por los medios, por irracionales que estos fueran. Un ejemplo de lo anterior está documentado en lo que se atinó llamar "La guerra de los mundos". Este fue un programa radial emitido el 30 de octubre de 1938 por la CBS y realizado por Orson Wells, donde se describía la invasión de los marcianos a la Tierra. Los oyentes pasaron el límite entre la ficción y la realidad, creyendo firmemente que estaban siendo invadidos por los extraterrestres, entraron en choque, comenzaron a huir frenéticamente, buscaron a sus seres queridos, se despidieron telefónicamente de sus amigos, avisaron a sus vecinos y hasta comenzaron a buscar en otros medios de comunicación las reacciones a estos hechos. Según el sociólogo Hadley Cantril (1940), "por lo menos seis millones de personas oyeron la emisión y como mínimo un millón de ellas se asustaron o se inquietaron".

En esta teoría el centro del modelo de comunicación era el receptor, toda vez que era el sujeto a intervenir a través de los mensajes, dejando de lado el contexto social en el que se movía y del 
cual se alimentaba para construir su visión del mundo.

En segundo lugar, encontramos las teorías de los "Efectos Limitados", que para los años 40 y revaluado el conductismo como instrumento para abordar las problemáticas sociales, se abre espacio a la psicología experimental y a la sociología. Aquí se transforma determinantemente el concepto de audiencia, entendiendo a esta como un grupo de individuos no tan pasivos sino, por el contrario, con un poder limitado para intervenir su realidad. En este espacio epistemológico podemos encontrar la "teoría de las diferencias individuales", la misma que comienza a plantear, como su denominación lo expresa, que los individuos tienen diferencias que los llevan a asumir de forma diferente los mensajes que reciben. Aquí la personalidad de los individuos ocupa un lugar preponderante que determina el valor simbólico que se le da al mensaje, estableciéndose el concepto de "atención selectiva". La atención selectiva consiste en que los sujetos tienden a exponerse a los mensajes que emiten los medios de acuerdo con sus intereses personales y predisposiciones; por lo tanto, realizan una selección más o menos consciente de qué es lo que desean ver y entender.

Para esta teoría existen cuatro categorías que influyen en un receptor al momento de enfrentarse a un mensaje: la primera es el "interés", que corresponde a la motivación que tiene el sujeto con respecto al tema del mensaje; la segunda es la "exposición selectiva", es decir, con el ánimo de evitar el conflicto, dicho interés se dirige en aquellos mensajes que más se adaptan a las actitudes y valores del receptor; la tercera categoría es la "percepción selectiva", que es la que determina la interpretación que el sujeto hace del mensaje de acuerdo con sus valores y actitudes; y por último, la cuarta categoría que corresponde a la "memoria selectiva", que establece que las personas suelen recordar mejor lo que favorece sus propios intereses en contraposición de aquellos que los contradicen.
Vistas las cosas así, el poder de los medios es relativo y no absoluto, pues depende de las actitudes y valores de las personas. Según los teóricos de la época, aquí la investigación abre la posibilidad de encontrar la forma adecuada de manipular, pues permite conocer las características de los sujetos a intervenir y diseñar los mensajes de acuerdo con sus expectativas.

Otra teoría que se sitúa en este espacio epistemológico de los "efectos limitados", es la de las "categorías sociales" y de los "dos pasos". La experimentación llevó a establecer que las características individuales pueden ser compartidas por un grupo social determinado, lo que, a su vez, garantiza la adopción de una conducta similar ante los mensajes emitidos por los medios. Aquí nace el concepto de "Target", aún utilizado en la comunicación moderna, especialmente en la publicidad para lograr una mayor efectividad en la emisión de sus mensajes.

Como investigador característico de este paradigma, encontramos a Paul Lazarsfeld, quien tras varios estudios de los fenómenos sociales, concluyó que los efectos de los mensajes están fuertemente determinados por el contexto social en el que está inserto el individuo. Es este, el contexto, el que le da las herramientas simbólicas para interiorizar los contenidos $y$, por ende, para valorarlos. Aquí el receptor es entendido como un sujeto en interacción con otros mediante un vínculo social que de manera consecuente incide en la conducta, legitima su posición ante el mundo.

Unido a esto se describe teóricamente el concepto de "líderes de opinión", que vendría a conformar un "segundo paso" entre el mensaje y la audiencia, influyendo significativamente en la toma de decisiones de los sujetos inmersos en un contexto determinado. En este punto se puede observar que el hecho de influenciar a otros no es tan simple; depende de muchos factores de carácter emocional y contextual. 
Pero las teorías de los "efectos limitados" no se quedan ahí; también encontramos más situada en la psicología que en la comunicación, a la teoría de la disonancia cognitiva. Esta expresa que el individuo genera una alta tensión cuando se enfrenta a dos ideas contradictorias o incompatibles entre sí. Sostiene que la persona que afronta este tipo de tensión tiende a la coherencia generando nuevas ideas o creencias que auto-justifiquen sus acciones o expresiones. Esta teoría nos muestra lo contradictorio del pensamiento humano, lo que hace más complejo el proceso de comunicación $y$, por ende, la forma de influir en su pensamiento a través de ella.

Ya hicimos un corto recorrido por las teorías que se sitúan en los paradigmas de los efectos omnipotentes y los efectos limitados de los mensajes mediáticos. Ahora pasemos a un tercer estadio, el de los "efectos importantes", llamado también "cognitivos". Aquí encontramos las teorías de la "agenda Setting" y la "espiral del silencio", las mismas que hacen un giro hacia las grandes posibilidades de los medios para manipular las audiencias, pero con la diferencia de que estos efectos son principalmente de tipo cognitivo.

La primera, la "agenda Setting" o "teoría de construcción de agenda", estipula que los medios de comunicación al momento de emitir sus mensajes realizan una jerarquización, estableciendo un temario que tendrá un impacto determinado e importante en la audiencia, definiéndole qué tema es más preponderante que otro. Esta línea de investigación fue la que generó el movimiento más significativo de la "Mass Communication Research", realizado por McCombs y Shaw en 1972.

A partir de la teoría de la "construcción de agenda" se establece que los medios generan una manipulación indirecta sobre la audiencia, pues carecen de la capacidad necesaria para indicarle a la gente cómo debe pensar, pero sí en qué debe pensar, estableciendo prioridades en la agenda y favoreciendo la construcción de unos imaginarios sociales determinados. Así, la lectura de la realidad depende de la interpretación que de ella realicen los medios de comunicación social.

La segunda teoría de este espacio epistemológico de los efectos importantes y cognitivos es, la "espiral del silencio", también denominada la "mayoría intimidatoria". Esta teoría parte del hecho del temor psicológico que tienen los seres humanos al aislamiento social, a no ser reconocidos por sus pares sociales, que los lleva a dudar de su propio juicio. Este miedo latente hace que el individuo trate de identificar la opinión de la mayoría para sumarse a ella; por lo tanto, desde esta perspectiva los medios de comunicación operan como formadores de esa mayoría, es decir, de consenso, otorgando a los periodistas la autoridad necesaria para diagnosticar el "clima de opinión" (Neumann, 1974).

Según la investigadora que desarrolló esta teoría, Noelle Neumann, este modelo genera una lógica donde se crea una espiral silenciosa, pues, mientras más se difunde una opinión dominante, más adeptos consigue, acalla las voces individuales y acelera el efecto de opiniones mayoritarias, construyendo un proceso de retroalimentación ascendente. Desde este punto de vista podemos concluir que la opinión pública como uno de los públicos fundamentales de las relaciones públicas, es susceptible de ser altamente manipulada a través de los medios de comunicación.

Para finalizar este aparte donde pretendemos buscar las conexiones teóricas entre funcionalismo y relaciones públicas, entremos al especio epistemológico de la audiencias activas. Aquí la teoría de los "usos y las gratificaciones" nos viene a determinar el camino a seguir. Esta teoría surge en contraposición al establecimiento de la audiencia como un ente pasivo, toda vez que es esta quien tiene el poder a determinar los contenidos mediáticos que se abordarán, la intensidad 
en la exposición y la motivación (interés) que los lleva a la utilización de un medio en particular. Denis McQuail (1983) al respecto establece que cada individuo hace una selección consciente y motivada por circunstancias personales de los contenidos que desea afrontar.

Antes de terminar este apartado es valioso y responsable establecer que existen varias versiones de esta perspectiva teórica en la investigación, algunas más situadas en los estudios culturales donde se hace una descripción de los fenómenos mediáticos y otras más funcionalistas, centradas en los efectos de los medios y los mensajes.

Ahora abordemos esta relación desde el otro paradigma científico de la teoría de la comunicación: el estructuralismo. Esta es una corriente de pensamiento de origen europeo en la que se resaltan los nombres de los científicos Reginald Radcliffe-Brown y Claude Lévi-Strauss. El primero fue un sociólogo y etnólogo inglés que realizó estudios comparativos de los principios estructurales de las relaciones humanas, también se le asocia a los orígenes del funcionalismo. Por su parte, el segundo, Claude Lévi-Strauss, es un antropólogo francés que afirmó que todos los fenómenos sociales, incluso los políticos, son también fenómenos lingüísticos, que a través de la hermenéutica se puede comprender el juego estructural que da sentido al discurso, es decir, las relaciones de un elemento con otros en una estructura es lo que aporta sentido, sintaxis. En principio se reconoce dicha sintaxis por los efectos, por sus productos; pero luego, y aquí entra el estructuralismo, hay que definirla desde las relaciones que se vinculan entre sí a los elementos que componen la estructura lingüística, profiriéndoles un valor de posición y, por ende, de significación. Entonces el objeto de estudio, como lo menciona Althusser, son los definidores y distribuidores de esas posiciones y funciones. Estas conceptualizaciones tienen grandes consecuencias en cuanto a la investigación de lo social y en particular de lo político.
Lévi-Strauuss define la estructura como una construcción racional de pensamiento y de ahí que critique fuertemente al funcionalismo, pues considera que pensar que todo en una sociedad funciona es un absurdo.

Otros estudiosos de esta corriente que revolucionaron los procesos investigativos fueron Michel de Foucault y Ronald Barthes. Foucault centra sus investigaciones en el discurso, el lenguaje y la estructura de los enunciados de las culturas; su preocupación científica se sitúa en el análisis de las formaciones discursivas en las que se presentan aserciones regulares. Por su parte, Barthes tomó el método estructuralista para desarrollar procesos investigativos dirigidos al campo literario, concretamente a la crítica literaria y desde esta perspectiva desarrolla la semiología referida a la ciencia general de los signos que estudia las grandes unidades significantes del discurso, clasificándolas en las siguientes dicotomías: lengua-habla; significado-significante; sintagmasistema, y denotación-connotación: referida a la expresión-contenido.

Bajo este paradigma se han realizado sendos estudios del discurso político. Es aquí donde encontramos la principal relación entre este modelo científico y las relaciones públicas, toda vez que recoge una de sus principales aristas como objeto de análisis, como es la política con sus procesos persuasivos.

Para finalizar este análisis en el que se trata de dilucidar la relación entre la teoría de la comunicación y las relaciones públicas, abordaremos el tercer paradigma, la teoría crítica de la comunicación. Este modelo se caracteriza por rechazar la realidad socio-histórica por considerarla irracional. Aquí Max Horkheimer, Theodor Adorno, Herbert Marcuse lideraron lo que se conoce la "Escuela de Francfort", que inició su labor en Alemania y luego por razones de la Segunda Guerra Mundial, la continuó en Nueva York. En la actualidad su mayor representante es el prolífico pensador ale- 
mán Jürgen Habermas. Esta corriente nació para oponerse a la teoría tradicional que se sustenta en la pura contemplación, que opera apoyada en principios generales y últimos, y presupone identidad e inmediatez en cuanto al sujeto-objeto y la adecuación con respecto al concepto y la cosa. De manera opuesta, la mirada crítica se sitúa en un punto medio entre el idealismo propuesto por Hegel y el irracionalismo.

La teoría crítica de la comunicación se caracteriza por partir de una dialéctica negativa en contraposición a la dialéctica positiva de Hegel, quien asume la realidad desde una perspectiva completamente racional. Por su parte, desde dialéctica negativa de la teoría crítica, Adorno afirma que no todo lo real es totalmente racional, rechazando la utopía positiva a través de la cual se puede determinar cómo será el futuro; al respecto Adorno (1944) expresa, "lo que sí es posible establecer, es cómo no debe ser el futuro, lo que permite poder criticar el presente". Otra característica fundamental de la teoría crítica es la mediación de los procesos socio-históricos y económicos en la conformación del objeto, es decir, todo hecho social está mediado por lo social, lo histórico y lo económico. Así las cosas, ninguna teoría es imparcial sino que está atravesada por intereses de carácter ideológico, haciendo que el investigador sea parte inherente del objeto social investigado.

Lo anterior ha llevado a los pensadores de la teoría crítica a asumir una posición clara frente a los hechos sociales que estudian, queriendo favorecer el compromiso político a través del análisis de las relaciones sociales de comunicación, esencialmente desde las formas estructurales de irrespeto que dañan y distorsionan las relaciones sociales de reconocimiento (Honneth, 2007). Complementando lo anterior, Rainer Forst (1999) con su definición de la teoría crítica nos da luces para comprender la relación existente entre este paradigma epistemológico y las relaciones públicas como praxis que favorece el desarrollo de las relaciones de poder a través de los discursos políticos deliberadamente planificados antes de ser emitidos por los medios. En consecuencia, Fosrt expresa que la teoría crítica explicaría y cuestionaría los factores que limitan la comunicación desde tres espacios,

Como teoría normativa, la teoría crítica argumenta en favor de la cohesividad de una esfera de integración comunicativa normativa, así como a favor de la realización de la posibilidad de un discurso social y político; como teoría socio-científica, explica los factores y estructuras que dificultan la infraestructura comunicativa social y que obstaculizan el discurso (por ejemplo mediante la exclusión de actores de la argumentación política y de la toma de decisiones); y como participante en conflictos políticos, argumenta para sustentar normas e instituciones que pueden ser defendidas por todos aquellos que están 'sujetos' a ellas (Forst 1999).

Sin embargo, es primordial resaltar que la teoría crítica no se queda en la mera descripción de los fenómenos sociales, sino que también propone un cambio social que se puede gestar a través de la visualización y conocimiento de la fuerzas de desigualdad que sirvan para instigar la generación de una acción política de emancipación dirigida a "disminuir la dominación y la desigualdad" (Rush, 2004). Al respecto David Held (1980) nos dice: "los teóricos críticos Adorno, Habermas, Horkheimer y Marcuse pretendieron establecer una sociedad libre y hacer patentes los obstáculos para su desarrollo".

La teoría crítica hace un análisis de las instituciones sociales, ideologías, discursos y formas de conciencia, que permita desvelar los estados de representación y dominación que limitan la autonomía en la toma de decisiones, con especial ahínco en las relaciones asimétricas de poder, los supuestos asumidos como realidades absolutas y las creencias (Alvesson y Deetz, 2000). De ahí 
que Marx y su materialismo dialéctico que dio pie al materialismo histórico, con su crítica hacia el capitalismo, sea el soporte epistemológico de la teoría crítica, la que, a su vez, en los medios de información y comunicación, encuentra un espacio para realizar una lectura analítica y crítica de la sociedad. Por ello no es extraño encontrar en las investigaciones que se realizan bajo esta plataforma científica el estudio de conceptos como: "mercantilización de la audiencia, estrategias de acumulación de medios, estética mercantilista, racionalidad tecnológica, manipulación, esfera proletaria contra-pública, públicos múltiples, uso emancipatorio de medios, uso represivo de medios, medios alternativos, medios radicales, fetiches de la comunicación, aparatos de ideología del Estado, la multitud, la circulación de luchas, hegemonía, lectura dominante, lectura opositora, lectura negociadora, función acumuladora de capital de los medios, función de los medios en la circulación de mercancías, función de legitimación de los medios, funciones de publicidad y relaciones públicas, función regenerativa de los medios, modelos de propaganda de los medios, acción comunicativa, comunicación dialógica, comuni- cación de discurso, capitalismo informacional transnacional", entre muchos más ${ }^{1}$.

Para redondear la idea del aporte de la teoría crítica a las ciencias de la comunicación y, por ende, a uno de sus vértices, las relaciones públicas, recogemos las palabras de Carl Marx: "lo fundamental no es entender el mundo (...) sino cambiarlo mediante la praxis, o la acción social reflexiva". Y es en esa praxis es donde se encuentran las técnicas de las relaciones públicas como instrumento de transformación social.

\section{CONCLUSIÓN}

Para concluir este aparte de nuestro estudio y a modo de resumen, presentamos el siguiente diagrama que pretende mostrar de manera gráfica la relación que existe entre los dos conceptos que venimos analizando. Relación de absoluta dependencia de la disciplina (relaciones públicas) a la ciencia (la comunicación) y como hilo que las ata, está la investigación que al final da como resultado desvelar las mejores prácticas para la persuasión.

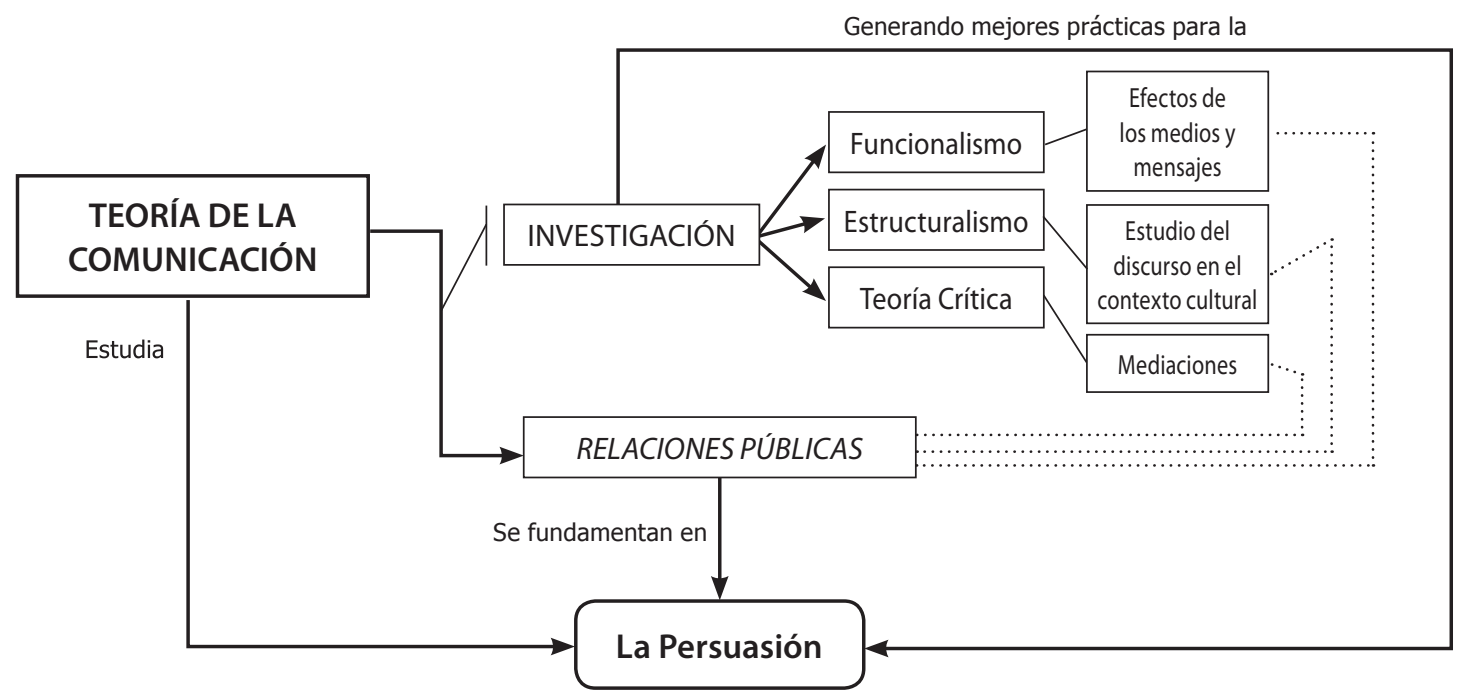

Fuente: elaboración propia

1 Extraído de: http://sites.google.com/site/glosariobitrum/ Home/teoria-critica-de-la-informacion 
